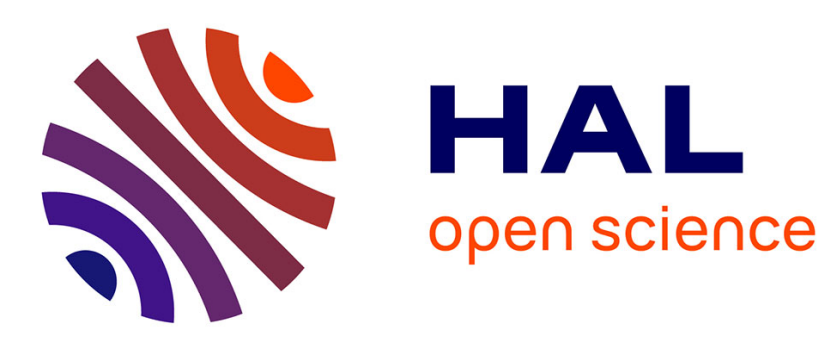

\title{
The speech focus position effect on jaw-finger coordination in a pointing task
}

Amélie Rochet-Capellan, Rafael Laboissière, Arturo Galvan, Jean-Luc Schwartz

\section{- To cite this version:}

Amélie Rochet-Capellan, Rafael Laboissière, Arturo Galvan, Jean-Luc Schwartz. The speech focus position effect on jaw-finger coordination in a pointing task. Journal of Speech, Language, and Hearing Research, 2008, 51 (6), pp.1507-1521. 10.1044/1092-4388(2008/07-0173 . hal-00282323

\section{HAL Id: hal-00282323 \\ https://hal.science/hal-00282323}

Submitted on 27 May 2008

HAL is a multi-disciplinary open access archive for the deposit and dissemination of scientific research documents, whether they are published or not. The documents may come from teaching and research institutions in France or abroad, or from public or private research centers.
L'archive ouverte pluridisciplinaire HAL, est destinée au dépôt et à la diffusion de documents scientifiques de niveau recherche, publiés ou non, émanant des établissements d'enseignement et de recherche français ou étrangers, des laboratoires publics ou privés. 


\section{The speech focus position effect on jaw-finger coordination in a pointing}

7 Amélie Rochet-Capellan ${ }^{\text {a) }}$, Rafael Laboissière ${ }^{\text {b,c, d) }}$, Arturo Galván ${ }^{\text {d) }}$, Jean-Luc Schwartz ${ }^{\text {a) }}$ 8

a) GIPSA-Lab, Département Parole et Cognition (ICP) UMR CNRS 5216 - INPG - Université Stendhal, Grenoble, France

20 Suggested running head: Focus position and jaw-finger coordination in a pointing task 21

$22{ }^{1}$ Corresponding author: amelie.rochet-capellan@gipsa-lab.inpg.fr, tel. (+33)(0)476574827, 23 fax. (+33)(0)4.76.82.43.35, INP Grenoble, 46 avenue Félix Viallet, 38031 GRENOBLE 24 CEDEX 1, France 


\section{Abstract}

26 Purpose: This paper investigates jaw-finger coordination in a task involving pointing to a 27 target while naming it with a 'CVCV (e.g. /'papa/) vs. CV'CV (e.g. /pa'pa/) word. According to 28 our working hypothesis, the pointing apex (gesture extremum) would be synchronized with the 29 apex of the jaw opening gesture corresponding to the stressed syllable.

30 Method: Jaw and finger motions were recorded using Optotrak. The effects of stress position 31 on jaw-finger coordination were tested across different target positions (near vs. far) and 32 different consonants in the target word (/t/ vs. /p/). Twenty native Portuguese Brazilian 33 speakers participated in the experiment (all conditions).

34 Results: Jaw response starts earlier and finger-target alignment period is longer for CV'CV 35 words than for 'CVCV ones. The apex of the jaw opening gesture for the stressed syllable appears synchronized to the onset of the finger-target alignment period (corresponding to the pointing apex) for 'CVCV words, and with the offset of that period for $\mathrm{CV}$ 'CV ones.

Conclusions: For both stress conditions, the stressed syllable occurs within the finger-target alignment period due to tight finger-jaw coordination. This result is interpreted as an evidence for an anchoring of the speech deictic site (part of speech that shows) in the pointing gesture.

Key-words: Deixis, Pointing, Jaw, finger-jaw coordination, speech-hand coordination, 
45

\section{Introduction}

Hand and mouth often work together in human behaviors, mainly in alimentation and communication. This link has motivated a large body of research. For example, Iverson and Thelen (1999) showed that spontaneous co-occurrence of hand and mouth movements appears right after birth. Then, around 6 to 8 months, hand and mouth start to mutually entrain each other in rhythmic activities characterized by manual and oral babbling. Gestures and speech are then produced sequentially at around 9 to 14 months and eventually synchronized at the age of 16 to 18 months. Interplay of hand and mouth motor control is also observed in adults' behavior. For example, when speakers open their mouth while grasping an object such as a fruit, the apertures of both the grasp and the mouth are adapted to the size of the object (Gentilucci et al., 2001). The observation of an action realized by one part of the body, e.g. bringing a fruit to the mouth, also affects the production of an action realized by the other, e.g. uttering a syllable (see Gentilucci et al., 2004; Gentilucci, 2003). Hand and mouth are also coupled in adults' rhythmic activities. For example, Kelso et al. (1981) found a 1 to 1 ratio between the frequency of the repetition of the word "stack" and the simultaneous repetition of a flexion-extension motion of the index finger. In addition, the co-occurrence of hand and mouth movements is clearly observable in face-to-face communication. The origin of this co-ocurrence seems to be motor rather than purely perceptual, since gestures are produced even in situations in which the interlocutor can't perceive them, such as in phone calls (Iverson and Goldin-Meadow, 1998).

According to McNeill (2000), a variety of gestures can occur in communication, ranging from gesticulations, which are global, non-conventionalized, and speech-dependent, to signs in signed languages, which are segmented, analytic, conventionalized, and performed without speech. This paper focuses on a particular type of gesture that can accompany speech in 
communication, namely pointing gestures. The global aim here is to link deixis, the component of language that allows referring to objects, with the capacity of synchronizing gesture and voice to show objects. This synchronization may depend on the properties of the motor coordination between hand and mouth, arising from pre-linguistic links between the two motor systems.

\section{Pointing gesture and language}

Our interest in pointing gestures and more particularly in their coordination with speech originates mainly from five observations reported in the literature. The first observation is that pointing gestures are the principal medium of shared attention, a basic function required for language acquisition (Tomasello et al., 2007). The second observation is that pointing gestures appear to be universal (Butterworth, 2003), despite variability in the form of the gesture across cultures (Haviland, 2000; Wilkins, 2003). The third observation is that pointing gestures are the first and the dominant communicative actions in infant communication. At 12 months, pointing gestures constitute $60 \%$ of infants' manual communicative gestures and are often accompanied by vocalizations (Butterworth, 2003). The fourth observation is that pointing gestures are at the cutting edge of language development. Goldin-Meadow and Butcher (2003) showed that the age at which children associate a pointing gesture with a word having complementary meanings determines the age of two-words productions (see also Volterra et al., 2005; Pizzuto et al., 2005 for similar conclusions). The fifth and last observation is that pointing gestures have been put forward as the canonical form of language demonstrative words (Haviland, 2000; Diessel, 1999). Drawing evidence from developmental and comparative psychology, Diessel (2006) argues that demonstrative words such as "this" or "that" serve the basic communicative function of joint (or shared) attention rather than a specific grammatical function. He provides evidences for considering demonstrative words as 
95

particular linguistic objects, defending their universal character and especially their specific and close link with pointing gestures.

Altogether, this body of research on the relationships between pointing gestures and language in general, and between pointing gestures and deixis in particular, led Abry et al. (2004) to consider the connection between hand and voice in deixis as a crucial step in language emergence. They proposed to derive speech and language from the necessity to localize the objects we need to talk about, which requires the hand and mouth coordination. Hence, the understanding of speech-showing and hand-pointing coordination could be considered as a key step to understand the emergence of language deixis.

In this framework, this paper investigates the effect of the position of the emphasized part of speech, namely speech focus (the part of speech that shows), on jaw-finger coordination in a task involving pointing at a target with the hand/finger while naming it.

\section{Processes underlying speech-pointing synchronization}

At least since McNeill's work (1981), it is well known that speech and hand gestures are coordinated in on-line face-to-face interactions. This phenomenon has motivated studies about the processes involved in speech-hand coordination, around, among others, the question of the interaction vs. modularity of the two systems. Most often, these studies used a dual-task paradigm: the participant provided both a verbal and a gestural response to a stimulus. The hand and speech dynamics in this dual task are compared to hand dynamics in a gesture-only task and speech dynamics in a speech-only task. For example, in Holender (1980), the task was to name a letter that appeared on a screen and press a key while in Castiello et al. (1991), it was to pronounce "tah" in response to a visual stimulus that indicated an object to grasp. 
120 More in line with our concerns, Levelt et al. (1985), and later Feyereisen (1997) used the

121 double task paradigm in order to study pointing gestures. The dual task was to point at an

122 object with the hand while verbally designating it using a "that object" or "this object"

123 utterance (e.g. "this lamp"). According to Levelt et al. (1985), pointing gestures present a

124 double interest for the study of speech and hand synchronization: first, they are strictly

125 dependent on the message being expressed and, second, the moment at which they reach their

126 target (now referred to as the pointing apex) can be easily detected.

127

128 Among others, Levelt et al.'s results showed that for utterances like "this lamp", the voice-onset

129 tends to be synchronized with the pointing apex. Hence, putting the target further from the

130 subject delays both the pointing apex and the voice-onset. The voice-onset also occurs later in

131 the dual task (when it is accompanied by the pointing gesture) than in the speech-only task. On

132 the other hand, the timing of the pointing apex is essentially the same in both gesture-only and

133 dual tasks. The authors interpret these results as evidence for an adaptation of speech

134 commands to brachiomanual commands rather than the reverse. A delayed verbal response in a

135 dual task as regards a speech-only task is also put forward in Holender (1980), Castiello et al.

136 (1991), and Feyereisen (1997).

137

138 However, all these studies measured the verbal response delay using the acoustic signal only,

139 without considering the speech articulators. As we will discuss in the next section, the processes

140 of speech-hand coordination might be better described and understood through the dynamical

141 interplay between the orofacial articulation and the hand-finger systems.

\section{Jaw-hand coordination rather than voice-hand coordination}

144 The motivation for investigating the articulatory motions in speech-hand coordination stems 
145 from two kinds of arguments. First, at a methodological level, speech is also a gestural system 146 much like pointing. Following Stetson (1951), a great number of studies have focused on the 147 articulators' motions, characterizing speech as the outcome of a motor system. As suspected by 148 Castiello et al. (1991) and Holender (1980), some motor events might happen before the voice 149 onset. Hence, it is legitimate to investigate when articulators start to move relative to the 150 pointing gesture. In addition, at a theoretical level, speech-pointing coordination has been 151 assumed to emerge in the course of ontogeny from a developmental meeting between the jaw 152 and arm-hand motor control (Ducey-Kaufmann et al., in press). According to MacNeilage and

153 Davis's Frame-then-Content scenario of speech development, speech motor control begins in 154 young babies with the mastering of the opening/closing oscillations of the jaw, which provides 155 the speech-frame (MacNeilage and Davis, 2000). The independent and coordinated control of 156 the tongue and the lips (the content) would be mastered later. In this frame-then-content sequence experimentally observed in the course of ontogeny (Munhall and Jones, 1998; Green et al., 2002), the jaw is considered as the carrier of speech gestures. Yet, MacNeilage and Davis

159 did not consider the role of manual gestures in speech acquisition. Different studies put forward 160 a link between the motor control development of brachiomanual and orofacial gestures.

161 Supporting evidences for this link comes from the relationship between the frequencies of hand 162 and jaw oscillations in babbling (Petitto et al., 2001; Iverson and Thelen, 1999; Ducey163 Kaufmann, 2007), what Ducey-Kaufmann et al. (in press) referred to as the sign-frame and 164 the speech-frame, respectively. According to them, the relationship between the frequencies 165 of the two systems would evolve toward a developmental meeting point between the speech 166 frame and the sign frame. This meeting point is suggested to be the basis of speech-hand 167 coordination and the background for the production of the first words. These two sets of 168 methodological and theoretical arguments, lead us to propose a jaw-hand rather than a voice169 hand investigation framework for studying speech and manual pointing coordination 
171 The question of interest in the present study concerns the candidate sites for the speech and

172 pointing gesture coordination: which part of the hand gesture is synchronized with which part of

173 the speech utterance? According to McNeill (1992), in speech-hand coordination, the hand

174 gesture stroke is executed in synchrony with the semantically co-expressive word. Moreover,

175 verbal deixis can be prosodic as well as grammatical (e.g. Lœvenbruck et al., 2005). When

176 considering the communicative aim of speech-hand association in deixis, it seems reasonable to

177 assume that the part of the discourse that shows should occur synchronously with the part of the

178 gesture that shows. Thus, synchronization of speech and hand pointing in face-to-face

179 communication could result in an attraction between the speech focus (the indexical word

180 and/or the stressed part of the utterance) and the pointing focus (the moment at which the

181 arm-hand-finger system is aligned with the target). This hypothesis is compatible with Levelt

182 et al.'s (1985) results, which show a tendency towards synchrony between voice-onset

183 corresponding to the demonstrative word ("this" or "that") and the hand-pointing apex.

184 Nevertheless, Levelt et al. did not vary the position of the speech deictic site, which was;

185 systematically at the beginning of the utterance (e.g. "this lamp" vs, "that lamp"). In this paper,

186 we propose to vary the position of speech focus in a simple way by varying the stressed syllable

187 in CVCV utterances. Our aim is to study how this variation influences the jaw-hand

188 coordination in a task consisting in pointing to a target while naming it with a CVCV word. Our

189 main hypothesis is that the hand pointing apex should be synchronized with the extremum (or

190 apex) of the jaw opening gesture corresponding to the stressed syllable, either the first syllable

191 in 'CVCV utterances (e.g. /'papa/) or the second syllable in CV'CV utterances (e.g. /pa'pa/). This

192 alignment could be reached either through adaptation of the jaw movement to a constant hand

193 movement in both 'CVCV and CV'CV sequences, or through a mutual adaptation, involving a

194 modification of both jaw and hand motions across word stress conditions. 


\section{Methods}

\section{Participants and language}

198 Brazilian Portuguese was chosen because it is one of the languages in which it is possible to

199 find pairs of words that differ only by stress position (e.g. 'CVCV vs. CV'CV). The subjects 200 were twenty native Portuguese Brazilian speakers (4 men and 16 women) aged 18 to 37 years 201 (mean: 28.3, standard deviation: 5.3). They were paid 8 euros per hour for their participation. 202 The participants were all right-handed, had no reported history of speech or hearing pathology 203 and were unaware of the purpose of the experiment.

\section{Experimental design}

The experiment involved a hand-pointing task associated to the utterance of a CVCV disyllable.

The main factor was the stress position in the CVCV dissyllable: stress on the first vs. the second syllable, e.g. /'papa/ vs. /pa'pa/. The consonant was either /p/ or /t/. The vowel /a/ was selected because it requires a large jaw opening gesture. Moreover, two spatial targets were used for the pointing gesture (near vs. far). The variation of both the consonant and the target 211 position contributed to focus participants' attention on the task. Hence, the experimental design consisted of three within-subjects two-level crossed factors: stress position (first vs. second), consonant (/t/ vs. /p/) and target position (near vs. far).

\section{Procedure}

217 The participants were seated at a table. The targets to point at and the item to pronounce were 218 projected simultaneously on a white screen in front of them using a projector (Figure 1, top). 
219 A black square pasted on the midline of the table, close to the participant's sagittal plane, 220 indicated the finger resting position. The participants were informed that a word and a red 221 smiley sign (the target) would appear on the screen. The target appeared to the participant's 222 right (Figure 1, bottom) either near (10 $\mathrm{cm}$ from midline) or far (50 cm from midline). In 223 order to make the joint gesture/pronunciation task more natural, participants were instructed 224 to use the word displayed as the name of the person represented by the smiley target. 225 Participants were instructed to simultaneously point with the index finger at and name the 226 target as soon as the color of the smiley sign changed from red to green. Prior to the 227 experiment, participants were briefly trained to become familiar with the task: they were 228 asked to simultaneously point at and name objects in the room. They also practiced reading 229 CVCV sequences aloud in order to make sure that they understood the stress instruction 230 properly. The experiment was divided into four blocks. One block contained 4 practice trials 231 followed by 40 experimental trials, 5 for each combination of stress position, consonant, and 232 target position. The order of the trials was randomized for each block and each participant. 233 Blocks were separated by 30s rest periods. In order to reduce anticipatory responses to the go 234 signal (smiley target becoming green), the red smiley duration was varied from trial to trial 235 (2.5 s mean, $0.15 \mathrm{~s}$ standard deviation, normally distributed). The green smiley target lasted 236 on the screen for $1 \mathrm{~s}$ in each trial.

\section{Data recording and post-processing}

239 Finger and jaw movements were recorded using Optotrak (Northern Digital, Inc.), an 240 optoelectronic position measurement system that tracks the three-dimensional motion of 241 infrared-emitting diodes (IREDs). The positions were sampled at $100 \mathrm{~Hz}$. IRED locations are 242 illustrated on Figure 1 (top). Two IREDs were pasted on the tip of participants' right 243 forefinger, one on the middle of the nail and the other on the medial side next to the nail. In so 
244 doing, at least one of the IREDs was visible by the cameras during the pointing movement, 245 even when participants supinated their hands at the motion apex. A third IRED was attached 246 to the participants' chin. It tracked a flesh point rather than the jaw itself. However, 247 considering the phonetic material in question (stop consonants associated with an open 248 vowel), the motion of this flesh point is a relevant indicator of jaw motion. Head motion was 249 measured by three IREDs attached to a plastic triangle, which was fixed by a strap around the 250 participant's head. The coordinates of the moving IREDs were projected into a fixed 251 referential, defined by three IREDs pasted on the table. Jaw position was then computed in 252 the head moving reference frame. Principal Component Analysis (PCA) was applied separately 253 to each of the three 3-D trajectories of the two finger IREDs and the jaw IRED. The first 254 principal component explained most of the variance for each IRED and for all participants: $25598.8 \%($ standard error $=0.2 \%)$ and $98.3 \%($ standard error $=0.3 \%)$ for the two finger IREDs and $25695.6 \%$ (standard error $=0.5 \%$ ) for the jaw IRED. This component was chosen to represent 257 finger and jaw movements. Signals were low-pass filtered at $15 \mathrm{~Hz}$ with a Butterworth. The 258 sound was simultaneously recorded and sampled at $16 \mathrm{kHz}$.

260 The recorded utterances were checked against the correct phonetic and stress instructions. 261 Trials with speech production errors were excluded from the dataset (in average, 4.1 trials per 262 subject, with a maximum of 11 errors for one participant, see table 1, first row). Correct trials 263 for which jaw or finger gestures were initiated before the go-signal were also discarded. This 264 mainly concerned one participant who made 39 initiation errors (Table 1, second row). For 265 the remaining data, trials for which the two finger IREDs were partially hidden from the 266 Optotrack cameras were not considered for the analysis ( 8.2 trials in average, see table 1, third 267 row). By default, the middle IRED was chosen for the analysis. When this IRED was masked 268 and the left one was visible, the left IRED was taken for the analysis (the mean correlation 
269 between the two finger IREDs is above .99 for each of the three coordinates $\mathrm{x}, \mathrm{y}$, and $\mathrm{z}$ ). 270 Similarly, trials for which the jaw IRED was partially hidden were discarded from the 271 analysis, which mainly concerned one participant for 12 trials (Table 1, fourth row). A three 272 within-subject factors ANOVA shows that stress position, consonant and target position do 273 not significantly affect either the number of utterance and initiation errors, or the number of 274 trials with hidden finger or jaw IREDs.

\section{Labeling and Measurements}

Figure 2 displays an example of signals and labeling for a /pa'pa/ trial. Onset and offset events of the finger and jaw movements correspond to $10 \%$ of peak velocity. All times correspond to the elapsed times from the go signal to the event.

For the jaw (Figure 2, second row), the analysis was focused on the two opening strokes for the /a/ vowels. $\mathrm{J}_{\mathrm{I} 1}$ and $\mathrm{J}_{\mathrm{A} 1}$ are the initiation and apex times for the first opening stroke (stroke onset and offset, respectively). Similarly, $\mathrm{J}_{\mathrm{I} 2}$ and $\mathrm{J}_{\mathrm{A} 2}$ are the initiation and apex times for the second opening stroke. For the finger, the trajectory can be split into three parts: the forward stroke, the plateau and the return stroke (see Figure 2, last row). The forward stroke corresponds to the pointing gesture toward the target. It starts at $\mathrm{P}_{\mathrm{I}}$ (initiation time of pointing gesture) and ends at $\mathrm{P}_{\mathrm{A}}$ (apex time of pointing gesture). The pointing plateau is the amount of to its rest position. This stroke was not considered here since it is not really part of the 292 pointing task. Note that Levelt et al. (1985) only investigated the pointing forward stroke. 293 Yet, the observation of a plateau in the apex position shows that the finger-pointing task does 
294 not end with the alignment of the finger and the target but rather with the onset of the return 295 stroke. In our study, for the finger motion analysis we considered both the forward stroke and 296 the plateau.

\section{Hypotheses}

299 Under the assumption that there is a tight temporal coordination of jaw and finger pointing 300 gestures, the apex of the jaw opening gesture corresponding to the stressed syllable should be 301 synchronized with the pointing apex. This might induce a significant effect of the stress 302 position on the delay between the apex of the first jaw opening gesture, $\mathrm{J}_{\mathrm{A} 1}$, and the apex of the pointing gesture, $\mathrm{P}_{\mathrm{A}}$, that should be shorter in the first-syllable stress condition than in the second-syllable stress one. The increase in the delay between $\mathrm{J}_{\mathrm{A} 1}$ and $\mathrm{P}_{\mathrm{A}}$ in the secondsyllable stress condition would result in the apex of the second jaw opening gesture, $\mathrm{J}_{\mathrm{A} 2}$,

306 being closer to $\mathrm{P}_{\mathrm{A}}$. This should occur regardless of the target position and of the utterance 307 consonant. Hence, the effect of stress position on the timing of the pointing apex relatively to the two jaw opening gestures apices should be similar for the two target positions and the two consonants. Finally, the effect of stress position on jaw-finger coordination could result from either an adaptation of jaw movement to hand movement (or the converse) or a mutual

311 adaptation between the two motor systems. This can be evaluated through the analysis of the effect of stress position on timing, duration and amplitude of finger and jaw gestures.

\section{Results}

315 Figure 3 shows the mean temporal position of jaw and finger events, computed for the 31620 participants, depending on stress position, consonant and target position. The effects of the experimental variations on each measured variable were tested using three-way (stress 
318 position, consonant, and target position) within-subject ANOVAs. The p-value for the 319 significance level was fixed at 0.05 .

\section{Initiation times}

324 The pointing motion starts on average $322 \mathrm{~ms}$ after the go signal (see $\mathrm{P}_{\mathrm{I}}$ values on Figure 3). 325 There is no significant main effect of any of the three factors on $\mathrm{P}_{\mathrm{I}}$. Contrastively, the 326 initiation of the first jaw stroke $\left(\mathrm{J}_{\mathrm{I} 1}\right)$ occurs significantly earlier in the second-syllable stress 327 condition $(476 \mathrm{~ms})$ than in the first-syllable stress one $(539 \mathrm{~ms})(\mathrm{F}(1,19)=15.9, \mathrm{p}<.001)$, 328 and for $/ \mathrm{t} /(488 \mathrm{~ms})$ as compared to $/ \mathrm{p} /(527 \mathrm{~ms}),(\mathrm{F}(1,19)=13.5, \mathrm{p}<.01)$. Neither the 329 interaction between stress position and consonant, nor that between stress position and target 330 position is significant. Hence, the onset of the jaw movement $\left(\mathrm{J}_{\mathrm{I} 1}\right)$ depends on stress position 331 and occurs later than the onset of the finger movement $\left(\mathrm{P}_{\mathrm{I}}\right)$. Analysis of $J_{I 1}-P_{I}$ delay shows 332 that $J_{I 1}$ is closer to $P_{I}$ in the second-syllable stress condition (149 ms) than in the first-syllable 333 stress one $(223 \mathrm{~ms})(\mathrm{F}(1,19)=14.1, \mathrm{p}<.01)$, and for the $/ \mathrm{t} /(166 \mathrm{~ms})$ as compared to $/ \mathrm{p} /$ $334(206 \mathrm{~ms})(\mathrm{F}(1,19)=13.3, \mathrm{p}<.01)$. Furthermore, $J_{I 1}-P_{I}$ is significantly shorter for the near 335 (176 ms) than for the far $(195 \mathrm{~ms})$ target position $(\mathrm{F}(1,19)=10.9, \mathrm{p}<.01)$. Interaction effects 336 on $J_{I 1}-P_{I}$ are not significant. Hence, the jaw starts to move after the finger but significantly 337 closer to the beginning of the finger movement when stress is on the second rather than on the 338 first syllable. Moreover, the effect of stress position on the delay between $P_{I}$ and $J_{I 1}$ results 339 from an effect on $\mathrm{J}_{\mathrm{I} 1}$ : the stress position has no significant effect on $\mathrm{P}_{\mathrm{I}}$.

\section{$340 \quad$ Apices times}

341 The pointing apex $\left(\mathrm{P}_{\mathrm{A}}\right)$ occurs $16 \mathrm{~ms}$ later in the far $(749 \mathrm{~ms})$ than in the near $(733 \mathrm{~ms})$ target 342 condition. The effect of target position is significant $(F(1,19)=9.2, p<.01)$. Stress position 
343 and consonant type do not have any significant effect on $\mathrm{P}_{\mathrm{A}}$. By contrast, the stress position 344 significantly influences the apices times of the jaw opening gestures. The apex of the first jaw 345 opening gesture $\left(\mathrm{J}_{\mathrm{A} 1}\right)$ occurs $101 \mathrm{~ms}$ earlier in the second-syllable stress condition (620 ms) 346 than in the first-syllable stress one $(721 \mathrm{~ms}),(\mathrm{F}(1,19)=54.0, \mathrm{p}<.0001)$. A similar delay 347 across stress conditions is observed for the apex of the second jaw opening gesture $\left(\mathrm{J}_{\mathrm{A} 2}\right)$ 348 which occurs on average $108 \mathrm{~ms}$ earlier in the second-syllable stress condition (900 ms) than 349 in the first-syllable stress one $(1008 \mathrm{~ms}),(\mathrm{F}(1,19)=54.8, \mathrm{p}<.0001)$. Target position effect is 350 also significant for both $\mathrm{J}_{\mathrm{A} 1}(\mathrm{~F}(1,19)=7.1, \mathrm{p}<.05)$ and $\mathrm{J}_{\mathrm{A} 2}(\mathrm{~F}(1,19)=5.9, \mathrm{p}<.05)$. The apices of both jaw opening gestures occur earlier in the near $\left(665 \mathrm{~ms}\right.$ for $\mathrm{J}_{\mathrm{A} 1}$ and $949 \mathrm{~ms}$ for $\left.\mathbf{J}_{\mathrm{A} 2}\right)$ than in the far $\left(677 \mathrm{~ms}\right.$ for $\mathrm{J}_{\mathrm{A} 1}$ and $959 \mathrm{~ms}$ for $\left.\mathrm{J}_{\mathrm{A} 2}\right)$ target condition. The increase of the target distance thus delays the apices of the two jaw opening gestures by about $10 \mathrm{~ms}$. This delay is equivalent to the non-significant delay observed for the onset of the jaw movement, $\mathrm{J}_{\mathrm{I} 1}$, and seems to partly compensate for the $16 \mathrm{~ms}$ delay observed for the pointing apex, $\mathrm{P}_{\mathrm{A}}$. Finally, the consonant has no significant effect on the apices times of the two jaw opening gestures.

In addition, the delay observed for $\mathrm{J}_{\mathrm{A} 1}$ in the first-syllable stress condition compared with the second-syllable one results in $\mathrm{J}_{\mathrm{A} 1}$ being closer to $\mathrm{P}_{\mathrm{A}}$ in the first case. The study of $J_{A 1}-P_{A}$ shows that $\mathrm{P}_{\mathrm{A}}$ occurs about $11 \mathrm{~ms}$ after $\mathrm{J}_{\mathrm{A} 1}$ in the first-syllable stress condition and about $362129 \mathrm{~ms}$ after $\mathrm{J}_{\mathrm{A} 1}$ in the second-syllable stress one. This effect of stress position is significant $363(\mathrm{~F}(1,19)=52.3, \mathrm{p}<.0001)$. On the other hand, neither the target position nor the consonant have a significant effect on $J_{A 1}-P_{A}$. In order to better characterize the temporal relationships between

365 finger and jaw apices, we computed the position of pointing apex, $\mathrm{P}_{\mathrm{A}}$, relatively to the apices 366 of the two jaw opening gestures, $\mathrm{J}_{\mathrm{A} 1}$ and $\mathrm{J}_{\mathrm{A} 2}$ :

$$
P_{A / J}=\frac{P_{A}-J_{A 1}}{J_{A 2}-J_{A 1}}, \text { in percent. }
$$


368 A value of $0 \%$ for $\mathrm{P}_{\mathrm{A} / \mathrm{J}}$ corresponds to a case for which $\mathrm{P}_{\mathrm{A}}$ occurs at the same time as $\mathrm{J}_{\mathrm{A} 1}$. A 369 value of $100 \%$ corresponds to a case for which $\mathrm{P}_{\mathrm{A}}$ is synchronized with $\mathrm{J}_{\mathrm{A} 2}$. Figure 4 (left) 370 shows $\mathrm{P}_{\mathrm{A} / \mathrm{J}}$ means and standard errors against stress conditions. It appears that $\mathrm{P}_{\mathrm{A} / \mathrm{J}}$ mean is 371 greater when the second syllable is stressed (47\%) rather than the first one (5\%) $372(\mathrm{~F}(1,19)=66.0, \mathrm{p}<.0001)$. The effects of target position and consonant type as well as the 373 interactions are not significant. In line with the jaw-finger synchronization hypothesis, stress 374 position influences the relative times of the apices of the jaw opening gestures and of the 375 pointing gesture. While the pointing apex is very close in time to the apex of the first jaw 376 opening gesture when the first syllable is stressed, it occurs at about an equal distance in time 377 from the apices of the two jaw opening gestures when the second syllable is stressed. 378 Strikingly, in this last condition, the pointing apex seems closely synchronized with the 379 initiation of the second opening gesture of the jaw, $\mathrm{J}_{12}$. In average, $\mathrm{P}_{\mathrm{A}}$ occurs just $1 \mathrm{~ms}$ after $\mathrm{J}_{12}$ 380 when the second syllable is stressed and $175 \mathrm{~ms}$ before $\mathrm{J}_{\mathrm{I} 2}$ when the first syllable is stressed 381 (see Figure 3). Moreover, in the second-syllable stress condition, the apex of the second jaw 382 opening gesture is very close to $\mathrm{P}_{\mathrm{R}}$, the onset of the pointing gesture return stroke (that is, the 383 offset of the pointing plateau).

\section{Offset of the pointing plateau $\left(\mathrm{P}_{\mathrm{R}}\right)$ relative to the jaw apices}

$386 \mathrm{P}_{\mathrm{R}}$ occurs later when the second syllable is stressed (906 ms) rather than the first one (860 ms) $387(\mathrm{~F}(1,19)=16.0, \mathrm{p}<.001)$ as well as when the target is far $(901 \mathrm{~ms})$ as compared to when it is 388 near $(864 \mathrm{~ms})(\mathrm{F}(1,19)=28.0, \mathrm{p}<.0001)$. The consonant factor as well as all the interactions 389 is not significant. The pointing plateau duration $\left(P_{R}-P_{A}\right)$ is significantly greater when the 390 second syllable is stressed $(157 \mathrm{~ms})$ rather than the first one $(127 \mathrm{~ms})(\mathrm{F}(1,19)=14.1$, $391 \mathrm{p}<.01)$. It is also significantly greater when the target is far $(152 \mathrm{~ms})$ rather than near $392(132 \mathrm{~ms})(\mathrm{F}(1,19)=13.9, \mathrm{p}<.01)$. As for $\mathrm{P}_{\mathrm{R}}$, neither the consonant factor, nor the 
393 interactions are significant. Analysis of the $J_{A 2}-P_{R}$ interval shows that $\mathrm{P}_{\mathrm{R}}$ occurs $5 \mathrm{~ms}$ after $394 \mathrm{~J}_{\mathrm{A} 2}$ in the second-syllable stress condition and $148 \mathrm{~ms}$ before $\mathrm{J}_{\mathrm{A} 2}$ in the first-syllable stress 395 condition. This effect of stress position on $J_{A 2}-P_{R}$ is significant $(\mathrm{F}(1,19)=89.3, \mathrm{p}<.0001)$. 396 The delay between $\mathrm{J}_{\mathrm{A} 2}$ and $\mathrm{P}_{\mathrm{R}}$ is also greater when the target is near ( $\left.85 \mathrm{~ms}\right)$ rather than far $397(58 \mathrm{~ms})(\mathrm{F}(1,19)=16.9, \mathrm{p}<.001)$ but does not depend on the consonant. Interactions on $398 J_{A 2}-P_{R}$ are not significant. Similarly to what was done for the pointing apex, we computed 399 the position of $P_{R}$ relative to the apices of the two jaw opening gestures:

$$
P_{R / J}=\frac{P_{R}-J_{A 1}}{J_{A 2}-J_{A 1}}, \text { in percent. }
$$

Figure 4 (right) shows that $\mathrm{P}_{\mathrm{R} / \mathrm{J}}$ is close to $100 \%$ for the second-syllable stress condition 402 (104\%) while it is close to $50 \%$ for the first-syllable stress condition $(51 \%) . \mathrm{P}_{\mathrm{R} / \mathrm{J}}$ is also greater when the target is far (82\%) compared to when it is near $(73 \%)$ and for $/ \mathrm{t} /(79 \%)$ as compared to $/ \mathrm{p} /(76 \%)$. The three main effects are significant (stress position: 405 $\mathrm{F}(1,19)=102.9, \quad \mathrm{p}<.0001 ; \quad$ target position: $\mathrm{F}(1,19)=12.4, \quad \mathrm{p}<.01 ; \quad$ consonant: $\mathrm{F}(1,19)=4.9, \mathrm{p}<.05)$ but none of the interactions are. When the first syllable is stressed, the finger leaves its apex position before the apex of the second jaw opening gesture, at about an equal distance in time from the apices of the two jaw opening gestures. Actually, as mentioned in the previous section, in the first-syllable stress condition, the finger even leaves its apex position $175 \mathrm{~ms}$ before the apex of the second jaw opening stroke. By contrast, in the second-syllable stress condition, the finger leaves its apex position just after the apex of the second jaw opening gesture is reached.

414 In summary, the pointing apex, $\mathrm{P}_{\mathrm{A}}$, is close to the apex of the first jaw opening gesture, $\mathrm{J}_{\mathrm{A} 1}$, 415 when the first syllable is stressed while it occurs at about the midpoint between the apices of 416 the two jaw opening gestures, $\mathrm{J}_{\mathrm{A} 1}$ and $\mathrm{J}_{\mathrm{A} 2}$, when the second syllable is stressed. In the second417 syllable stress condition, the jaw events $\left(\mathrm{J}_{11}, \mathrm{~J}_{\mathrm{A} 1}, \mathrm{~J}_{\mathrm{I} 2}\right.$ and $\left.\mathrm{J}_{\mathrm{A} 2}\right)$ occur earlier than in the first- 
418 syllable stress condition and the onset of the pointing gesture return $\left(\mathrm{P}_{\mathrm{R}}\right)$ is delayed. These

419 two facts result in $\mathrm{J}_{\mathrm{A} 2}$ being close to $\mathrm{P}_{\mathrm{R}}$. By contrast, the timing of the pointing forward stroke

420 does not depend on stress position. The increase of the target distance delays the pointing 421 apex but does not significantly influence its time position relatively to the apices of the jaw 422 opening motions: $\mathrm{P}_{\mathrm{A} / \mathrm{J}}$ is approximately the same in the two target conditions. This originates 423 from the fact that the apices of the jaw opening gestures are delayed when the target is far 424 compared to when it is near. Regardless of the experimental conditions, the stress in speech 425 always occurs sometime during the pointing plateau, either at the plateau onset for 'CVCV 426 words or at the plateau offset for $\mathrm{CV}^{\prime} \mathrm{CV}$ words. This results in the entire pointing plateau 427 occurring before the onset of the second jaw opening stroke when the first syllable is stressed 428 and after it when the second syllable is stressed. More precisely, the pointing plateau occurs 429 during the jaw closure stroke after the stressed vowel in the first-stress syllable condition and 430 during the jaw opening stroke toward the stressed vowel when the second syllable is stressed.

431 The finger and jaw motion will now be investigated in detail in order to further characterize 432 the impacts of stress, target and consonant on each system separately.

\section{Detailed description of finger forward and jaw opening strokes}

\section{Finger forward stroke}

436 The previous analysis showed that the pointing onset, $\mathrm{P}_{\mathrm{I}}$, does not depend on the experimental 437 condition while the pointing apex, $\mathrm{P}_{\mathrm{A}}$, occurs significantly later when the target is far than 438 when it is near. This timing pattern implies a greater duration of the forward stroke (computed 439 as $\left.P_{A}-P_{I}\right)$ when the target is far $(431 \mathrm{~ms})$ rather than near $(406 \mathrm{~ms})(\mathrm{F}(1,19)=26.3$, $440 \mathrm{p}<.0001$, see Figure 5, first row, right). Neither the effect of stress position, nor the effect of 441 consonant on the duration of the pointing forward stroke are significant. The amplitude of this 442 stroke (computed as the distance between the pointing spatial positions at $\mathrm{P}_{\mathrm{A}}$ and $\mathrm{P}_{\mathrm{I}}$, Figure 5, 
443 first row, left) is also greater when the target is far $(423 \mathrm{~mm})$ compared to when it is near $444(275 \mathrm{~mm})(\mathrm{F}(1,19)=2222.0, \mathrm{p}<.0001)$. The $2 \mathrm{~mm}$ difference observed in the first-syllable 445 stress condition $(348 \mathrm{~mm})$ compared to the second-syllable stress one $(350 \mathrm{~mm})$ is also 446 significant $(\mathrm{F}(1,19)=8.3, \mathrm{p}<.01)$ but does not significantly interact with target position. The 447 consonant does not have a significant effect on the amplitude of the pointing forward stroke. 448 Hence, the pointing forward stroke is mainly influenced by target position: the alignment of 449 the finger with the target requires greater amplitude and duration when the target is far 450 compared to when it is near. This leads to consider that the pointing forward stroke is "target451 driven": its main objective is the alignment of the finger with the target. Consequently, the 452 speech system may have to adapt in order to achieve the relative timing pattern between the 453 apices of finger and jaw opening gestures, as previously observed.

\section{Jaw opening strokes}

456 As described above, the initiations and apices events of the jaw opening strokes clearly 457 depend on the experimental conditions. The duration of the first opening stroke (computed as $458 J_{A 1}-J_{I 1}$, Figure 5, second row, right) is $39 \mathrm{~ms}$ greater when the first syllable is stressed 459 (183 ms) rather than the second one $(144 \mathrm{~ms})(\mathrm{F}(1,19)=26.2, \mathrm{p}<.0001)$. It is also $37 \mathrm{~ms}$ greater for $/ \mathrm{t} /(182 \mathrm{~ms})$ compared to $/ \mathrm{p} /(145 \mathrm{~ms})(\mathrm{F}(1,19)=14.5, \mathrm{p}<.01)$. The interaction between stress position and consonant is also significant: the effect of stress position is larger for /p/ (first-syllable: $168 \mathrm{~ms}$, second-syllable: $122 \mathrm{~ms}$ ) than for /t/ (first-syllable: $197 \mathrm{~ms}$,

463 second-syllable: $167 \mathrm{~ms}),(\mathrm{F}(1,19)=5.5, \mathrm{p}<.05)$. However, target position does not 464 significantly influence the duration of the first opening stroke. Similarly, the amplitude of the 465 first jaw stroke (distance between the jaw spatial positions at $\mathrm{J}_{\mathrm{I} 1}$ and $\mathrm{J}_{\mathrm{A} 1}$, Figure 5 , second 466 row, left) is greater when the first syllable is stressed $(12.5 \mathrm{~mm})$ than when the second one is $467(9.6 \mathrm{~mm})(\mathrm{F}(1,19)=21.1, \mathrm{p}<.001)$. Consonant also has a significant effect: the mean 
amplitude of the first opening gesture is greater for $/ \mathrm{p} /(11.7 \mathrm{~mm})$ than for $/ \mathrm{t} /(10.3 \mathrm{~mm})$ $(\mathrm{F}(1,19)=9.7, \mathrm{p}<.01)$. Neither target position, nor the interactions is significant. Contrary to the first opening stroke, the duration of the second opening stroke $\left(J_{A 2}-J_{I 2}\right.$, Figure 5, third row, right) is greater when the second syllable is stressed $(152 \mathrm{~ms})$ rather than the first one $(100 \mathrm{~ms})(\mathrm{F}(1,19)=42.1, \mathrm{p}<.0001)$ and for $/ \mathrm{p} /(138 \mathrm{~ms})$ as compared to $/ \mathrm{t} /(114 \mathrm{~ms})$ $(\mathrm{F}(1,19)=47.1, \mathrm{p}<.0001)$. There is a significant interaction between stress position and consonant $(\mathrm{F}(1,19)=8.2, \mathrm{p}=.05)$ : the effect of stress position is greater for $/ \mathrm{t} /$ (first-syllable: $84 \mathrm{~ms}$, second-syllable: $145 \mathrm{~ms}$ ) than for /p/ (first-syllable: $117 \mathrm{~ms}$, second-syllable: $159 \mathrm{~ms}$ ). Target position does not significantly influence $J_{A 2}-J_{I 2}$. A similar pattern is observed for the amplitude of the second stroke (difference between jaw spatial positions at $J_{12}$ and $J_{A 2}$, Figure 5, third row, left) which is greater when the second syllable is stressed $(7.5 \mathrm{~mm})$ rather than the first one $(3.2 \mathrm{~mm})(\mathrm{F}(1,19)=40.3, \mathrm{p}<.0001)$ and for $/ \mathrm{p} /(6.7 \mathrm{~mm})$ compared to $/ \mathrm{t} /$ $(4.0 \mathrm{~mm})(\mathrm{F}(1,19)=45.8, \mathrm{p}<.0001)$. There is also a significant interaction between stress position and consonant $(\mathrm{F}(1,19)=5.7, \mathrm{p}<.05)$ : the effect of stress position is greater for $/ \mathrm{t} /$ 482 (first: $1.6 \mathrm{~mm}$, second: $6.4 \mathrm{~mm}$ ) than for $/ \mathrm{p} /$ (first: $4.8 \mathrm{~mm}$, second: $8.7 \mathrm{~mm}$ ). There is no significant effect of target position. These results show that in order to produce stress as instructed, speakers increase both the duration and the amplitude of the jaw opening stroke corresponding to the stressed syllable. The specific articulatory configurations of $/ \mathrm{p} /$ and $/ \mathrm{t} /$ result in significant effects of the consonant factor on the amplitude and the duration of the 487 jaw opening strokes. However, these effects of consonant appear to have no influence on the timing of the apices of the jaw opening gesture. Finally, the target position does not have a significant effect on the amplitude and the duration of the jaw opening strokes: increase in distance to the target induces a delay around $10 \mathrm{~ms}$ for all jaw events studied here. These 491 results support the view that the timing of the pointing apex relatively to the timing of the 492 apices of the jaw opening gestures mainly originates from an adaptation of the jaw. 
494 In summary, the analyses show that jaw-finger coordination basically consists in 495 synchronizing the pointing apex with the apex of the first jaw opening gesture when the first 496 syllable is stressed, and synchronizing the onset of the finger return gesture with the apex of 497 the second jaw opening gesture when the second syllable is stressed. This pattern seems to 498 rely on four types of adaptation:

499 (1) An adaptation of the finger pointing forward stroke to the spatial target: amplitudes and 500 durations increase when the target is far rather than near;

501 (2) An adaptation of the jaw to the phonetic goal: specific durations and amplitudes 502 correspond to /p/ vs. /t/, and amplitudes and durations are greater for stressed vs. unstressed 503 syllables;

504 (3) An adaptation of the jaw to the pointing forward stroke. When the first syllable is stressed, 505 whichever the spatial target is, the apex of the jaw opening gesture corresponding to the 506 stressed syllable is synchronized with the pointing apex. When the second syllable is stressed, 507 the delay between the apices of the two jaw opening gestures decreases, possibly allowing 508 synchronization between the pointing apex and the onset of the jaw opening gesture 509 corresponding to the second syllable;

510 (4) An adaptation of the duration of the pointing plateau, possibly compensating for the 511 incomplete finger-jaw apex synchrony when the second syllable is stressed. In this condition, 512 the increase of the duration of the pointing plateau allows for the apex of the jaw opening 513 stroke corresponding to the stressed syllable to occur within the finger to target alignment 514 period.

516 These results will now be discussed in the light of previous observations on speech-hand 517 coordination and within the framework of the jaw-hand/finger coordination hypothesis. 


\section{Discussion}

520 The change in stress position from a 'CVCV to a $\mathrm{CV}$ 'CV clearly influences the jaw-finger

521 coordination. However it does so though in a different way than we have predicted. There are

522 bidirectional adaptations from the jaw to the hand and from the hand to the jaw, which are 523 superimposed on the intrinsic target-driven behaviors corresponding to each system. We shall 524 discuss these three components (intrinsic behavior, jaw to hand and hand to jaw adaptations) 525 separately, and conclude on the way the two systems could be coupled in a dynamic system 526 approach.

\section{A pointing task and a speech task}

529 Obviously, the first point that must be made in this discussion is that, apart from any link

530 between speech and hand gestures, the hand and speech systems reach their respective targets 531 regardless of the individual requirements on each system. In the pointing task, the target must 532 be designated and the movement must be adapted to the target position, which involves larger 533 and longer movements when the target is far compared to when it is near. In the speech task, a 534 speaker has to utter the right consonants with the right stress pattern, which involves an 535 increase of the amplitude and/or the duration of the opening gesture for the stressed syllable. 536 The phonetic identity of the consonant (labial vs. coronal) influences the initiation times of 537 the jaw opening strokes but not their apices' times. It also affects the amplitude and duration 538 of the jaw opening strokes. Asymmetry in the jaw cycles for labial and coronal constrictions 539 in CV syllables is a phenomenon also observed in the repetition of CVCV words when speech 540 rate is increased. One possible explanation for this finding is that, for anatomical reasons, the 541 position of the jaw has a stronger influence on the position of the lower lip than on the position of the tongue (Rochet-Capellan and Schwartz, 2007a). 


\section{The jaw meets the hand}

545 As regards the first and major connection between the two systems, it appears that speech 546 adapts to the hand rather than the reverse and that this adaptation is related to the jaw 547 movements. Our prediction was that the synchronization between the apex of the jaw opening 548 stroke corresponding to the stressed syllable and the apex of the pointing gesture would be a 549 stable attraction point for jaw-finger coordination. This appears to be the case only when the 550 first syllable is stressed. In this case, the observed large delay between the beginning of the 551 pointing gesture and the beginning of the first jaw opening gesture is in accordance with 552 previous results obtained using the dual-task paradigm (see Introduction section). When the second syllable is stressed, the delay between the onsets of the pointing gesture and the jaw movement is reduced due to an early onset of the jaw movement. However, this is not enough for the apex of the pointing gesture to be synchronized with the apex of the second jaw opening gesture. It could seem surprising that when the second syllable is stressed, the onset 557 of the jaw movement occurs $148 \mathrm{~ms}$ (on average) after the onset of the hand movement, while 558 the apex of the second jaw opening stroke occurs $151 \mathrm{~ms}$ after the apex of the pointing gesture. Initiating the first jaw opening gesture at the same time as the pointing gesture could

560 be sufficient for the apex of the second jaw opening gesture to be synchronized with the apex 561 of the pointing gesture. The hand then compensates this failed synchronization during its 562 return to rest phase, as we shall discuss later. However, in terms of jaw adaptation, the synchronization seems partly unachieved. This does not mean that there is no meeting point 564 between the jaw and the hand when the second syllable is stressed. In this condition, the jaw 565 produces the first cycle early enough to entirely incorporate the pointing plateau inside the 566 second cycle. Therefore, the general working hypothesis that "the part of the discourse that 567 shows is related to the part of the gesture that shows" is verified. The movement of the jaw is 
organized such that the pointing plateau unambiguously occurs within the appropriate temporal domain of the spoken utterance that is the jaw cycle corresponding to the stressed syllable. This specifies the "deictic sites" we were looking for.

There seems to exist another meeting point that we had not predicted: when the second syllable is stressed, the finger reaches its apex more or less exactly at the same time as the jaw reaches its highest position, which is likely to closely correspond to the consonantal contact time for the second syllable (between the lips for $/ \mathrm{p} /$, or between the tongue and the palate for $/ \mathrm{t} /$ ). Interestingly, this is reminiscent of the synchrony put forward by Attina et al. (2006) between the hand target and the achievement of the consonantal closure in cued speech. This manuallyaugmented speech communication system involves hand positions and finger configurations added to the speech flow at a syllabic rhythm providing complementary information for deaf people to almost perfectly understand oral communication. In their study of cued speech production by French speakers, Attina and colleagues found a clear synchrony between the apices of hand movements achieving their adequate position for a given syllable, and the consonantal closure times in the corresponding speech.

In summary, "the jaw meets the hand" in the sense that the jaw adapts the onset of its movement in order for the pointing plateau to occur within the jaw cycle for the stressed syllable. This adaptation depends on the specific pointing and speech requirements. It occurs within a temporal window providing two possible meeting points for the pointing gesture apex: one corresponding to the apex of the first jaw opening gesture (when the first syllable is stressed) and another corresponding to the onset of the second jaw opening gesture (when the second syllable is stressed). The adaptation is achieved through the adequate delay of the onset of the jaw movement. If the target to point at is far, the pointing stroke is longer by about $16 \mathrm{~ms}$ 
593 and the onset of the jaw movement is delayed by about $10 \mathrm{~ms}$.

\section{The hand meets the jaw}

596 There is also a clear hand/finger adaptation to the movement of the jaw. It appears that the

597 hand waits for the apex of the jaw opening stroke corresponding to the stressed vowel to 598 occur before initiating its return stroke. This is illustrated by the observed significant effect of 599 stress position on the pointing plateau offset. To our knowledge, this is the first experimental 600 evidence of such adaptation of the pointing gesture to speech. This could be the way the hand 601 "corrects" for the lack of jaw-finger synchrony at the apex time that is by providing another 602 meeting point thanks to the expansion of the plateau duration. This ensures that the jaw 603 opening gesture apex corresponding to the stressed syllable does occur within the pointing 604 plateau in all cases.

605

607 Altogether there appears to be a bidirectional link between the hand/finger and the jaw. This 608 could be implemented by a series of local adaptations from one to the other, driven by 609 specific temporal commands. The fact that there are simultaneous specific requirements for 610 both systems rather suggests a kind of coupling between two dynamic systems, with the stress 611 command specifying the adequate sites of synchronization. Actually, in the debate about 612 modularity vs. interactivity of the motor control of speech and hand-pointing systems, it has 613 been assumed that when the speech and the hand systems move at the same time, the brain 614 would coordinate them as a single structure. In this framework, Kelso et al. (1981) showed 615 that rhythmic tasks involving speech and hand movements displayed preferential phasing 616 relationships between the articulators and the hand, as two coupled oscillator systems. Hence, 617 according to these authors, speech-hand coordination should be described inside a coupled- 
618 oscillators modeling framework, such as the "Haken-Kelso-Bunz" (HKB) model introduced

619 by Haken et al. (1985) for bimanual coordination. Other contributions to the dynamic system 620 approach of speech-hand coordination showed that the link between the two systems is not 621 absolute (Smith et al., 1986) and also depends on high-level cognitive factors (see Treffner 622 and Peter, 2002, for an improvement of the HKB model using intentional and attentional 623 factors). However, all these contributions support the view that the two systems could be 624 linked through their relative oscillatory frequencies. In addition, developmental studies suggested a ratio of 2 to 1 between the preferential oscillatory frequencies of the jaw and the hand performing pointing gestures (Ducey-Kaufmann et al., in press, Ducey-Kaufmann, 2007). This implies that at most two syllables could be achieved within one pointing gesture without influencing the pointing gesture. In a preliminary study (Rochet-Capellan et al., 2007b), we showed that for a task consisting of pointing and naming a target with a 1-, 2-, 3vs. 4-CV syllable word twice in rapid succession (e.g. /pa/+gesture and /pa/+gesture again),

631 the delay between the apices of the two pointing gestures is the same for 1- and 2-CV words 632 while it significantly increases from 2- to 3-CV words. This preliminary result provides some 633 kind of confirmation of the 2 to 1 preferential ratio.

635 Finally, the systematic delay of the speech gesture relative to the pointing gesture, together 636 with the large adaptation of speech to the hand gesture, suggest that the speech response could 637 be anchored in the pointing gesture through the online monitoring of the hand movement. 638 This could explain why Levelt et al. (1985) observed an effect of pointing perturbation on 639 speech only if the perturbation occurred at the beginning of the hand gesture. Thus, the speech 640 response would be carried by the pointing gesture, in agreement with the proposal that the 641 manual activity drives the coordination with the oral system (Iverson and Thelen, 1999). This 642 hypothesis would need further investigation, especially about the question of the information 
643 used by the speech system to initiate its response.

644

\section{Conclusion}

646 Taken together, the results agree with the idea that speech focus is anchored in the pointing

647 gesture for deictic expressions. This anchoring seems to be supported by a synchronization of 648 the speech-frame (the jaw cycle) with the sign-frame (the pointing gesture) as suggested in 649 the "Vocalize to Localize" framework for the origins of language. This results from two 650 independent levels of speech adaptation. First, the effects of stress position and consonant 651 order show an "internal" adaptation of the jaw opening gestures to the phonetic goal. In 652 addition, the effect of spatial target position suggests an "external" adaptation for the 653 synchronization with the pointing gesture within the adequate deictic site.

654

655 Further investigation will be needed to better understand the coordination of the jaw and hand 656 in deictic tasks. But the interesting point about this study is that there $i$ s coordination, 657 implemented in a more or less complex way in the speaker's brain, and that this coordination 658 can be put forward and studied by analyzing online behavior in various linguistic tasks 659 involving pointing using the voice and the hand.

\section{Acknowledgement}

662 This work is part of the "Patipapa" project funded by the French Ministry of Research (Action 663 Concertée Incitative "Systèmes Complexes en Sciences Humaines et Sociales"). Rafael 664 Laboissière works as a researcher at CNRS. We also wish to thank Christian Abry and 665 Coriandre Vilain for insightful discussions, Marion Dohen for proofreading this manuscript, 666 and the two anonymous reviewers for their helpful comments. 


\section{References}

668

669

670

671

672

673

674

675

676

677

678

679

680

681

682

683

684

685

686

687

688

689

690

691

692

693

Abry, C., Vilain, A., and Schwartz, J. (2004). Introduction : Vocalize to Localize? A call for better crosstalk between auditory and visual communication systems researchers : From meerkats to humans. Interaction Studies, 5(3): 313-325.

Attina, V., Cathiard, M.-A., and Beautemps, D. (2006). Temporal measures of hand and speech coordination during French Cued Speech production, In: S. Gibet, N. Courty, \& J.F. Kamp (Eds.): GW 2005, Lecture Notes in Artificial Intelligence, vol. 3881, (pp. 13-24). Springer-Verlag.

Butterworth, G. (2003). Pointing is the royal road to language for babies. In: S. Kita (Ed.), Pointing: Where Language, Culture, and Cognition meet (pp. 9-33). Lawrence Erlbaum Associates.

Castiello, U., Paulignan, Y., and Jeannerod, M. (1991). Temporal dissociation of motor responses and subjective awareness. A study in normal subjects. Brain, 114 (Pt 6)(NIL): $2639-55$.

Diessel, H. (1999). Demonstratives: Form, Function, and Grammaticalization. Typological Studies in Language, 42, John Benjamins.

Diessel, H. (2006). Demonstratives, joint attention, and the emergence of grammar. Cognitive Linguistics 17: 463-489.

Ducey-Kaufmann, V. (2007). Le cadre de la parole et le cadre du signe : un rendez-vous développementale (The speech frame and the sign frame: a developmental rendez-vous), $\mathrm{PhD}$ thesis, Sciences du langage, Université Stendhal, Institut National Polytechnique, Grenoble.

Ducey-Kaufmann, V., Abry, C., and Vilain, C. (In press). When the speech frame meets the sign frame in a developmental framework. In Emergence of Language Abbilities : Ontogeny and phylogeny, Lyon, France. ELA.

Feyereisen, P. (1997). The competition between gesture and speech production in dual-task paradigms. Journal of Memory and Language, 36(1): 13-33. 
694 Gentilucci, M. (2003). Grasp observation influences speech production. European Journal 695 of Neuroscience, 17: 179-184.

696 Gentilucci, M., Benuzzi, F., Gangitano, M., Grimaldi, S. (2001). Grasp with hand and 697 mouth: a kinematic study on healthy subjects. Journal of Neurophysiology. 86: 16856981699.

699 Gentilucci, M., Santunione, P., Roy, A.C., Stefanini, S. (2004). Execution and observation of 700 bringing a fruit to the mouth affect syllable pronunciation. European Journal of $701 \quad$ Neuroscience, 19: 190-202.

702 Goldin-Meadow, S. and Butcher, C. (2003). Pointing toward two-word speech in young 703 children. In S. Kita (Ed.), Pointing: Where language, culture, and cognition meet (pp. 85704 107). Lawrence Erlbaum Associates.

705 Green, J., Moore, C., and Reilly, K. (2002). The sequential development of jaw and lip 706 control for speech. Journal of Speech, Language, and Hearing Research, 45: 66-79.

707 Haken, H., Kelso, J. A. S., and Bunz, H. (1985). A theoretical model of phase transitions in 708 human hand movements. Biological Cybernetic, 51(5): 347-356

709 Haviland, J. B. (2000). Pointing, gesture spaces, and mental maps. In D. McNeill (Ed.), $710 \quad$ Language and gesture (pp. 13-46).

711 Holender, D. (1980). Interference between a vocal and a manual response to the same 712 stimulus. In G. Stelmach and J. Requin (Eds.), Tutorials in Motor Behavior (pp. 421-432). 713 North Holland Publishing Company.

714 Iverson, J. and Goldin-Meadow, S. (1998). Why people gesture as they speak. Nature, $715 \quad 396: 228$.

716 Iverson, J. and Thelen, E. (1999). Hand, mouth, and brain : The dynamic emergence of speech 717 and gesture. Journal of Consciousness Studies, 6: 19-40.

718 Kelso, J. A. D., Tuller, B. and Harris, K. S. (1981). A "Dynamic Pattern" perspective on the 719 control and coordination of movement. In P.F. MacNeilage (Ed.), The production of $720 \quad$ speech (pp. 137-173). New York: Springer-Verlag. 
721

722

723

724

725

726

727

728

729

730

731

732

733

734

735

736

737

738

739

740

741

742

743

744

745

746

747

Levelt,W. J. M., Richardson, G. and Heij,W. L. (1985). Pointing and voicing in deictic expressions. Journal of Memory and Language, 24: 133-164.

Lœvenbruck, H., Baciu, M., Segebarth, C. and Abry, C. (2005). The left inferior frontal gyrus under focus: an fMRI study of the production of deixis via syntactic extraction and prosodic focus. Journal of Neurolinguistics, 18: 237-258.

MacNeilage, P. and Davis, B. (2000). On the origins of intenal structure of word forms. Science, 288: 527-531.

McNeill, D. (1981). Action, thought and language. Cognition, (10) :201-208.

McNeill, D. (1992). Hand and Mind. Chicago: University of Chicago Press.

McNeill, D. (2000). Introduction. In D. McNeill (Ed.), Language and gesture (pp. 1-10).

Munhall, K. and Jones, J. (1998). Articulatory evidence for syllabic structure. Behavioral and Brain Science, 21: 524-525.

Petitto, L., Holowka, S., Sergio, L. and Ostry, D. (2001). Language rhythms in baby hand movement. Nature, 413(6851): 35-36.

Pizzuto, E., Capobianco, M. and Devescovi, A. (2005). Gestural-vocal deixis and representational skills in early language development. Interaction Studies. Social Behaviour and Communication in Biological and Artificial Systems, 6(2): 223-252.

Rochet-Capellan, A. and Schwartz J-L. (2007a). An articulatory basis for the Labial-toCoronal effect: /pata/ seems a more stable articulatory pattern than /tapa/. Journal of Acoustic Society of America, 121(6): 3740-3754.

Rochet-Capellan, A., Schwartz J-L., Laboissière, R. and Galván, A. (2007b). Two CV syllables for one pointing gesture as an optimal ratio for jaw-arm coordination in a deictic task: A preliminary study. In proceedings of EurocogSci07, the European cognitive Science conference, pp. 608-613, Delphi, Greece.

Stetson, R. H. (1951). Motor Phonetics (North-Holland, Amsterdam), 2nd ed.

Smith, A., McFarland, D. H. and Weber, C. M. (1986). Interactions between speech and finger movements: an exploration on the dynamic pattern perspective. Journal of Speech 
and Hearing Research, 29(4): 471-80.

749 Tomasello, M., Carpenter, M. and Liszkowski U. (2007). A new look at infant pointing. Child $750 \quad$ Development, 78(3):705-722.

751 Treffner, P. and Peter, M. (2002). Intentional and attentional dynamics of speech-hand 752 coordination. Human Movement Science, 21(5-6): 641-97.

753 Volterra, V., Caselli, M. C., Capirci, O., and Pizzuto, E. (2005). Gesture and the emergence 754 and development of language. In M. Tomasello and D. Slobin (Eds.), Beyond nature755 nurture- Essays in honor of Elizabeth Bates (pp. 3-40). Mahwah, N. J.: Lawrence Erlbaum 756 Associates.

757 Wilkins, D. (2003). Why pointing with the index finger is not a universal (in sociocultural and 758 semiotic terms). In S. Kita (Ed.), Pointing: Where language culture and cognition meet, 759 (pp. 171-215). Lawrence Erlbaum Associates. 


\section{Tables}

\section{Table 1:}

763 Number of rejected trials over all 20 participants and all experimental conditions: mean 764 number, standard error (Se), minimum and maximum number of utterance errors (incorrect 765 pronunciation), initiation errors (response before the go-signal), correct trials for which the 766 two finger IREDs were partially masked and for which the jaw IRED was partially masked, 767 see text for detail.

768

769

\begin{tabular}{l|llll} 
& Mean & Se & Min & Max \\
\hline Utterance error & 4.1 & 0.86 & 0 & 11 \\
Initiation error & 2.35 & 1.94 & 0 & 39 \\
Masked finger & 8.2 & 1.50 & 0 & 21 \\
Masked jaw & 0.75 & 0.60 & 0 & 12 \\
\hline
\end{tabular}


770

$771 \quad$ Figures

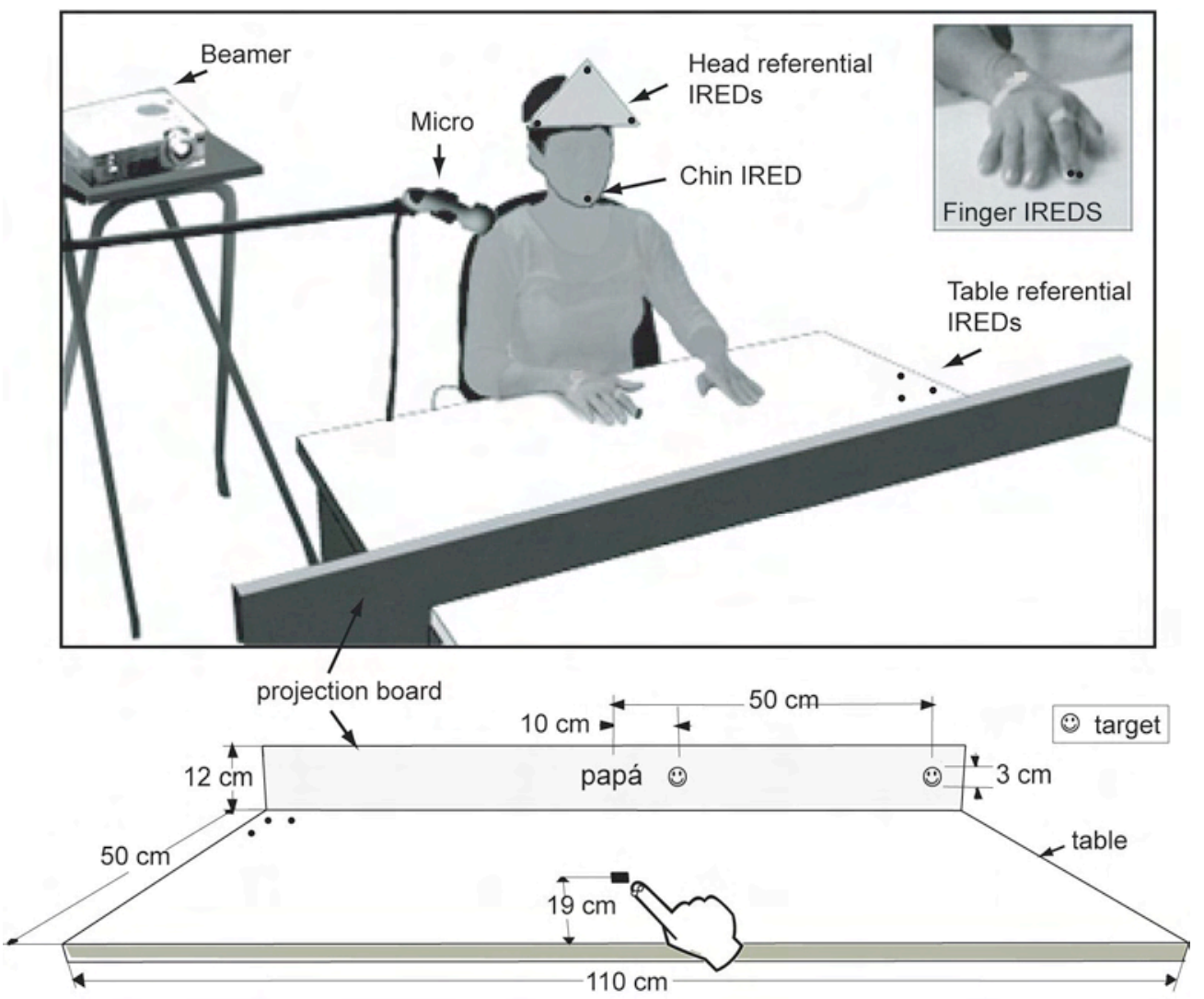

$773 \quad$ Figure 1 

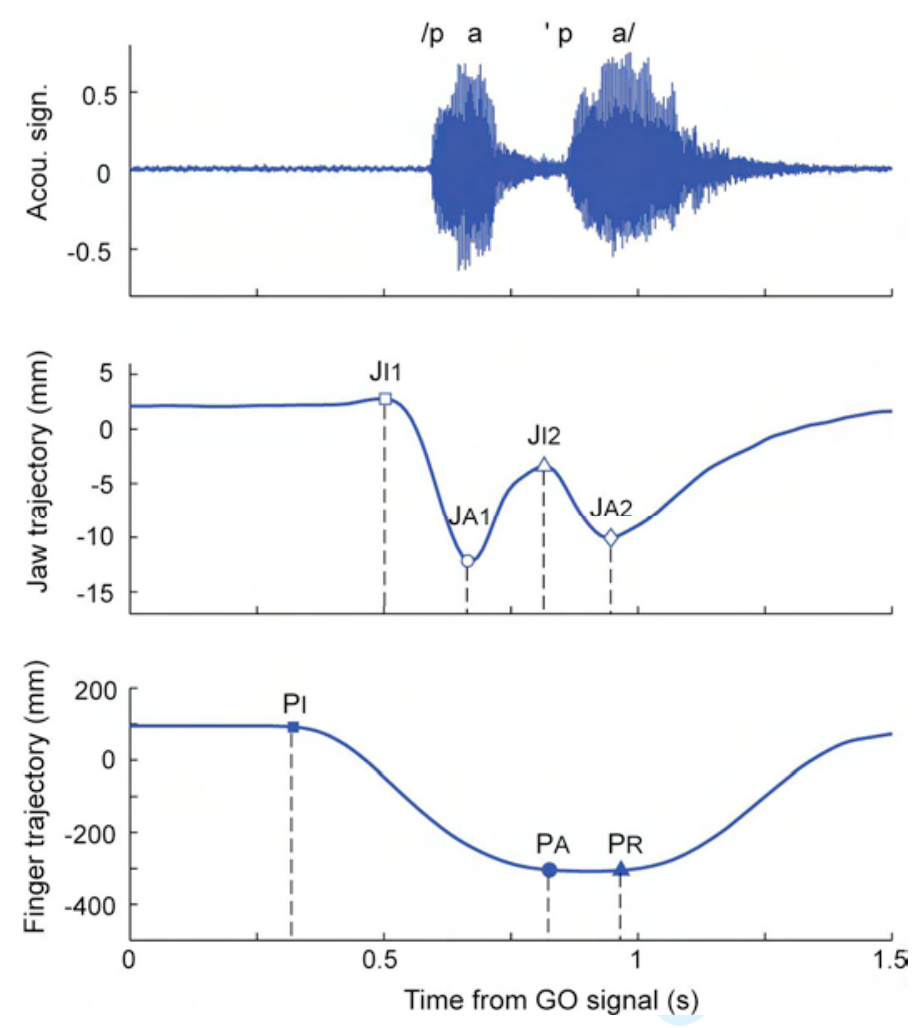

774

$775 \quad$ Figure 2 

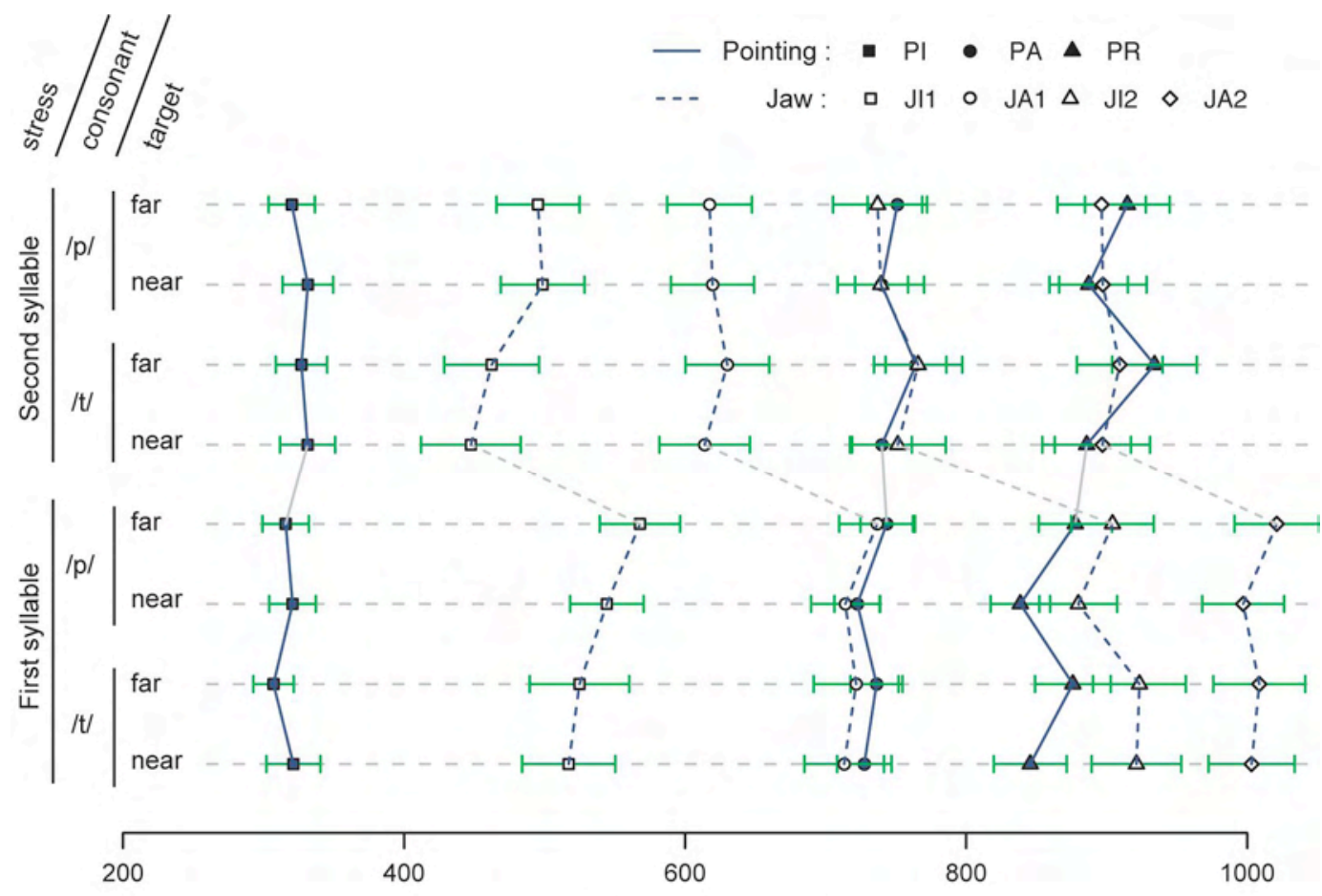

$777 \quad$ Figure 3 

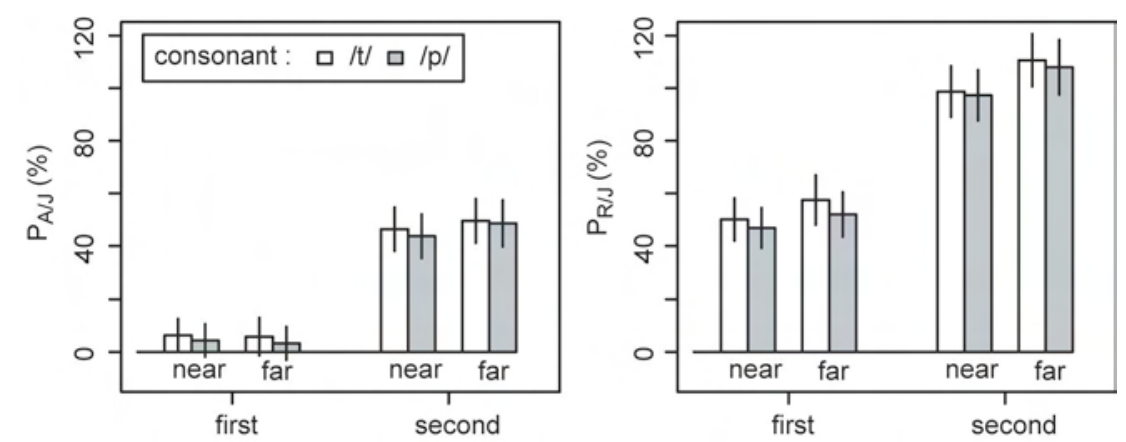

778

Stress position $\mathrm{X}$ Target position

779

$780 \quad$ Figure 4 


\section{1}
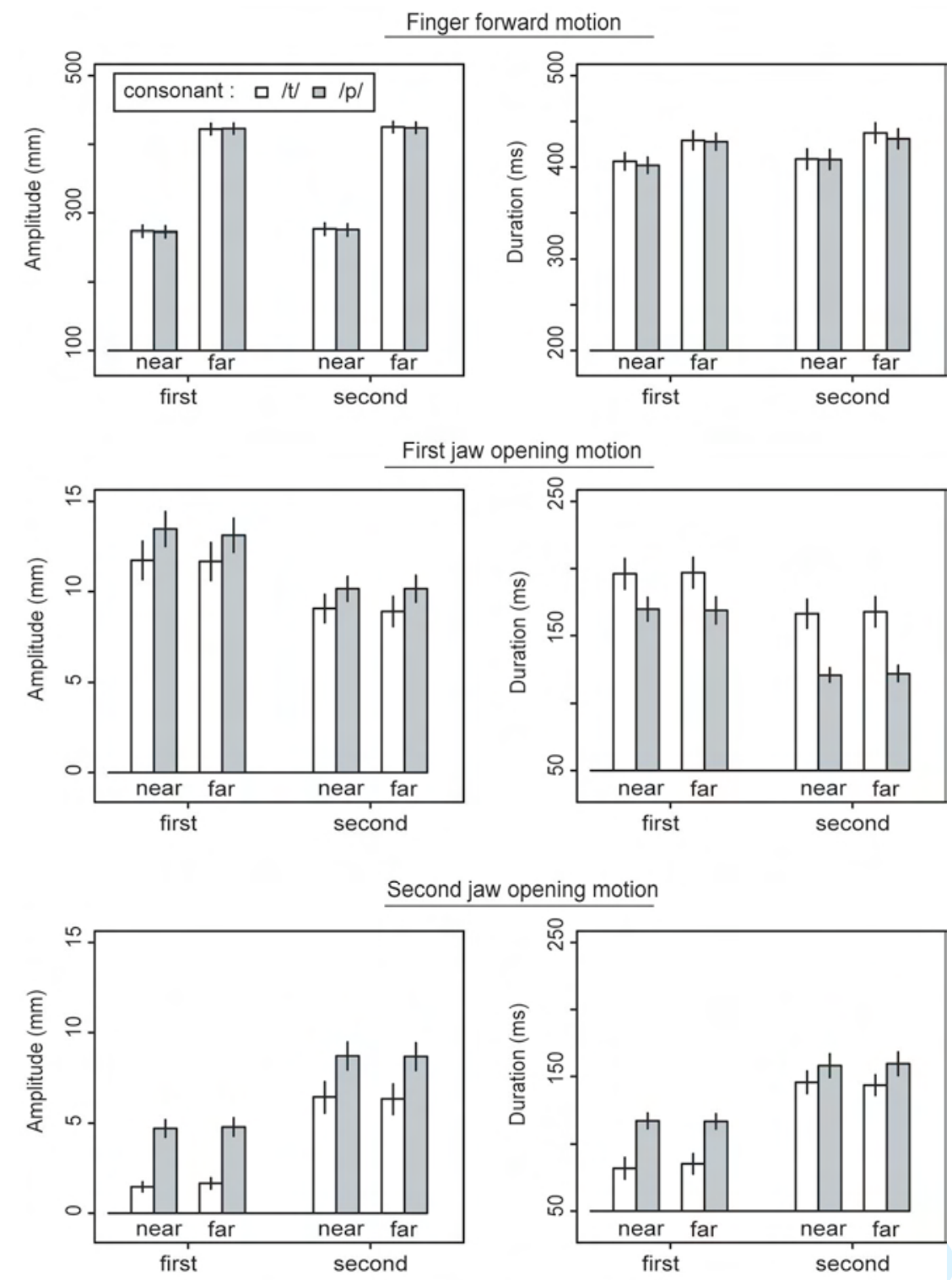

782

Stress position $\mathrm{X}$ Target position

\section{$783 \quad$ Figure 5}




\section{Figures captions}

$785 \quad$ Figure 1:

786 Experimental setup (top) and projection dimensions (bottom). The participants pointed at, and 787 named a smiley sign projected on a screen in front of them. Finger and jaw movements were 788 captured using Optotrak (in front of the participant) with two IREDs for the finger, one for the 789 jaw (chin IRED), three for the head (head IRED referential), and three on the table (referential

790 for all moving IREDs). The target name appeared in the midline of the visual field (e.g. $791 / \mathrm{pa} \mathrm{pa} /)$ and the pointing target on the right side, either at a near $(10 \mathrm{~cm})$ or a far $(50 \mathrm{~cm})$ 792 position.

$794 \quad$ Figure 2:

795 Example of signals and labeling for a /pa'pa/ trial. Top panel: acoustic signal; middle panel: 796 jaw trajectory; bottom panel: finger trajectory. Onsets and offsets of strokes are defined as the 797 instant when velocity reaches $10 \%$ of the maximum value during the corresponding stroke.

$798 \mathrm{~J}_{\mathrm{I} 1}, \mathrm{~J}_{\mathrm{I} 2}$ and $\mathrm{J}_{\mathrm{A} 1}, \mathrm{~J}_{\mathrm{A} 2}$ respectively correspond to the onset and apex (offset) times of the first and 799 second jaw opening gestures. $\mathrm{P}_{\mathrm{I}}$ and $\mathrm{P}_{\mathrm{A}}$ correspond to the onset and apex (offset) times of the 800 pointing forward stroke. $\mathrm{P}_{\mathrm{R}}$ is the onset time of the finger return movement. Note that, in this 801 example, even though stress position affects the second syllable, the amplitude of the jaw 802 movement is smaller for the second syllable than for the first one. This corresponds to the 803 general pattern observed in this experiment (see jaw opening movement panels in Figure 5).

804

$805 \quad$ Figure 3:

806 Means of the elapsed time from the go signal to the pointing and jaw events relative to stress 807 position (first vs. second syllable), consonant (/t/ vs. /p/) and target position (near vs. far). $\mathrm{P}_{\mathrm{I}}$, $808 \mathrm{P}_{\mathrm{A}}$ and $\mathrm{P}_{\mathrm{R}}$ respectively correspond to the onset, the apex and the onset of the return of the 
809 finger pointing movement. $\mathrm{J}_{\mathrm{I} 1}, \mathrm{~J}_{\mathrm{A} 1}$ and $\mathrm{J}_{\mathrm{I} 2}, \mathrm{~J}_{\mathrm{A} 2}$ respectively correspond to the onset and the 810 apex of the first and the second jaw opening strokes.

811

$812 \quad$ Figure 4.

813 Means and standard errors of the time of the pointing apex $\left(\mathrm{P}_{\mathrm{A} / \mathrm{J}}\right.$, left $)$ and of the time of the 814 onset of the pointing return $\left(\mathrm{P}_{\mathrm{R} / \mathrm{J}}\right.$, right $)$ relative to the apices of the two jaw opening gestures, 815 depending on stress position (first vs. second syllable), target position (near vs. far) and 816 consonant (/t/ vs. /p/).

817

$818 \quad$ Figure 5.

819 Means and standard errors of the amplitude and the duration of the finger forward stroke (first 820 row) and of the two jaw opening strokes (second and third rows) depending on stress position 821 (first vs. second syllable), target position (near vs. far) and consonant (/t/ vs. /p/). 


\section{Table 1:}

Number of rejected trials. For the 20 participants and all experimental conditions: mean number, standard error (Se), minimum and maximum number of: utterance errors (incorrect pronunciation); initiation errors (response before go-signal); correct trials with the two finger IREDs partially masked and with the jaw IRED partially masked, see text for detail.

\begin{tabular}{l|llll} 
& Mean & Se & Min & Max \\
\hline Utterance error & 4.1 & 0.86 & 0 & 11 \\
Initiation error & 2.35 & 1.94 & 0 & 39 \\
Masked finger & 8.2 & 1.50 & 0 & 21 \\
Masked jaw & 0.75 & 0.60 & 0 & 12 \\
\hline
\end{tabular}




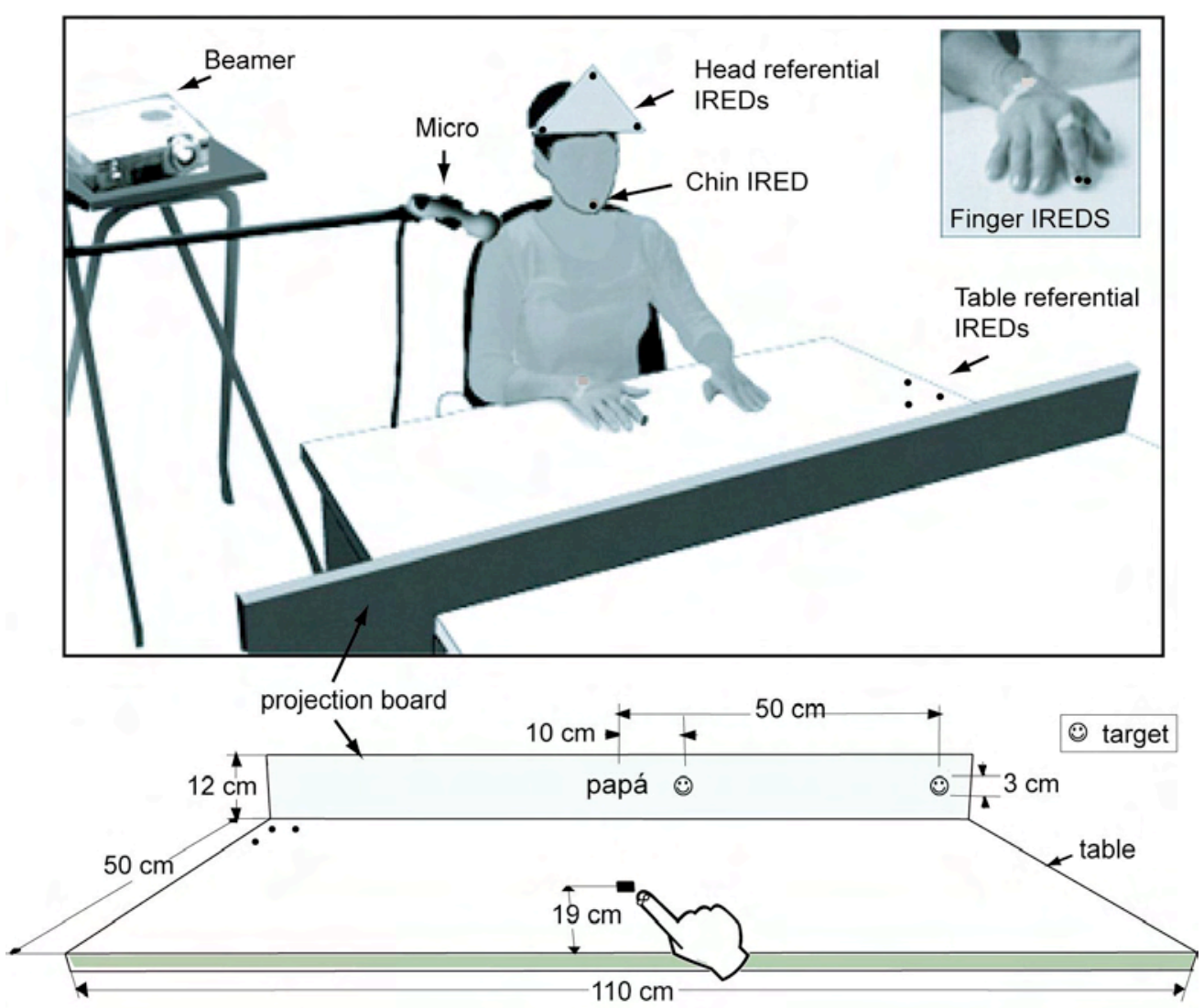

Figure 1: Experimental setup (top) and projection dimensions (bottom). The participants pointed at, and named a smiley sign projected on a screen in front of them. Finger and jaw movements were captured using Optotrak (in front of the participant) with two IREDs for the finger, one for the jaw (chin IRED), three for the head (head IRED referential), and three on the table (referential for all moving IREDs). The target name appeared in the midline of the visual field (e.g. /pa'pa/) and the pointing target on the right side, either at a near $(10 \mathrm{~cm})$ or a far $(50 \mathrm{~cm})$ position. $130 \times 111 \mathrm{~mm}(300 \times 300 \mathrm{DPI})$ 

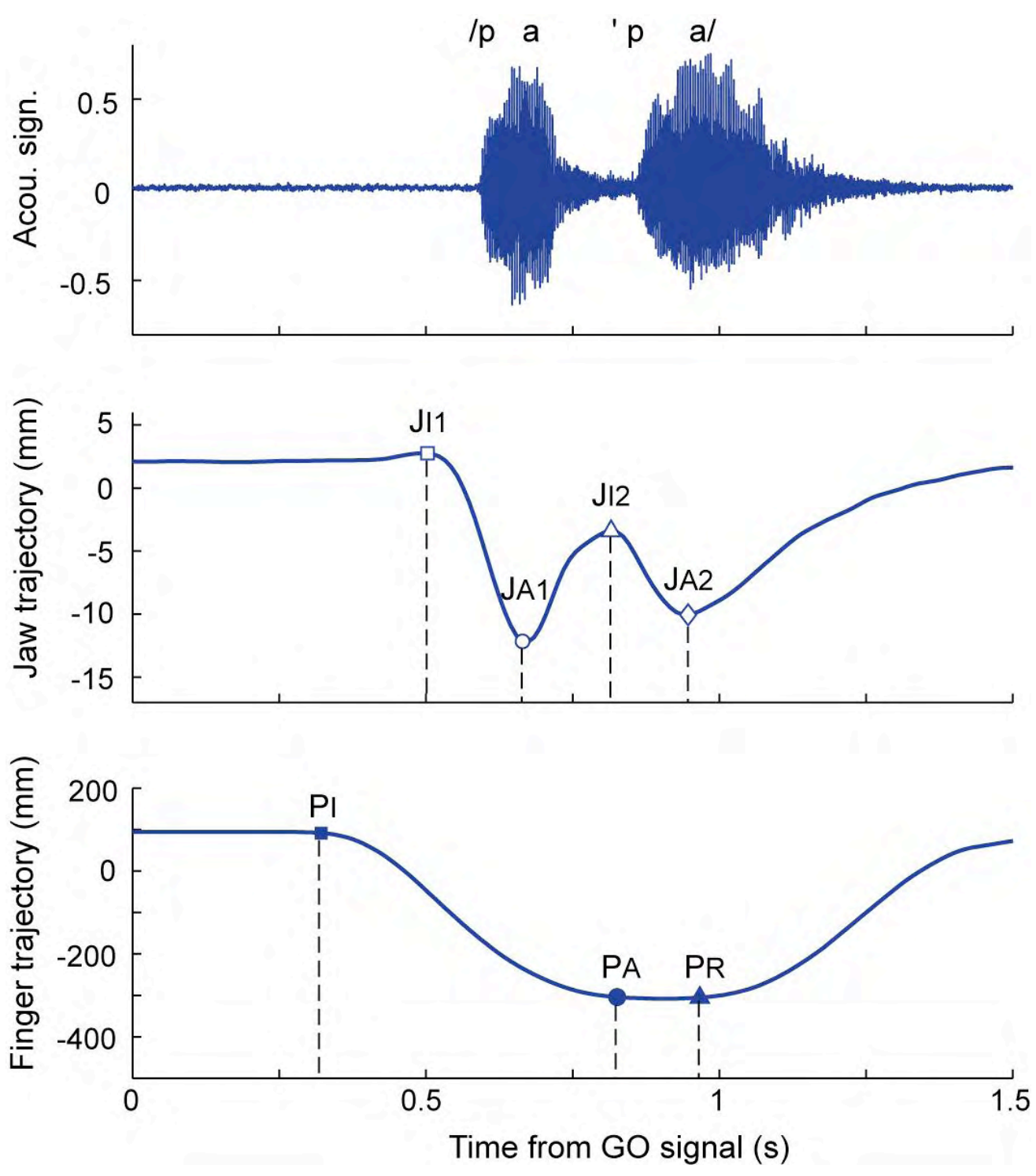

Figure 2: Example of signals and labeling for a /pa'pa/ trial. Top panel: acoustic signal; middle panel: jaw trajectory; bottom panel: finger trajectory. Onsets and offsets of strokes are defined as the instant when velocity reaches $10 \%$ of the maximum value during the corresponding stroke. JI1, JI2 and JA1, JA2 respectively correspond to the onset and apex (offset) times of the first and second jaw opening gestures. PI and PA correspond to the onset and apex (offset) times of the pointing forward stroke. PR is the onset time of the finger return movement. Note that, in this example, even though stress position affects the second syllable, the amplitude of the jaw movement is smaller for the second syllable than for the first one. This corresponds to the general pattern observed in this experiment (see jaw opening movement panels in Figure 5). 

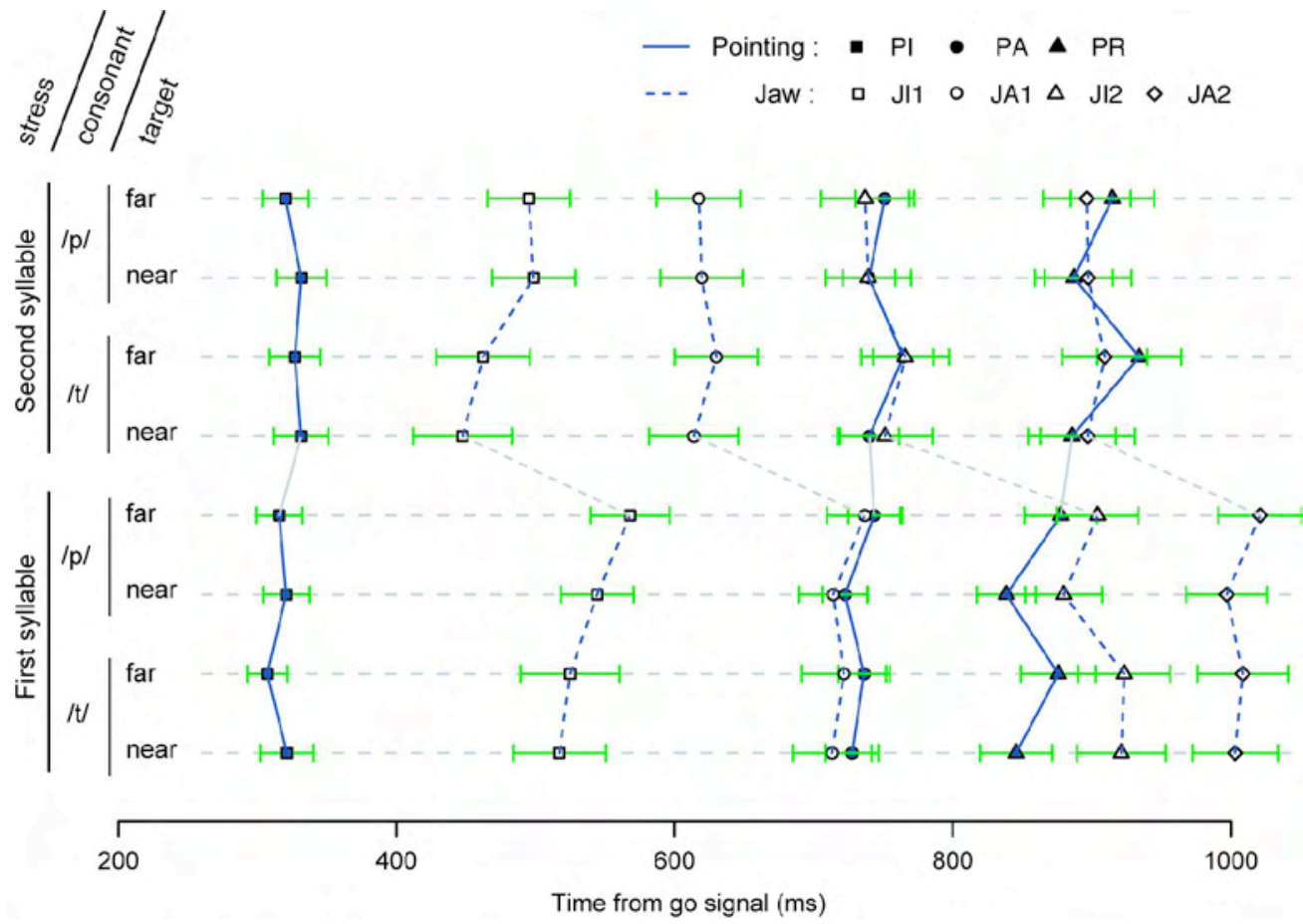

Figure 3: Means of the elapsed time from the go signal to the pointing and jaw events relative to stress position (first vs. second syllable), consonant $(/ t / v s$. / $/$ /) and target position (near vs. far). PI, PA and PR respectively correspond to the onset, the apex and the onset of the return of the finger pointing movement. JI1, JA1 and JI2, JA2 respectively correspond to the onset and the apex of the first and the second jaw opening strokes.

$139 \times 97 \mathrm{~mm}(300 \times 300 \mathrm{DPI})$ 

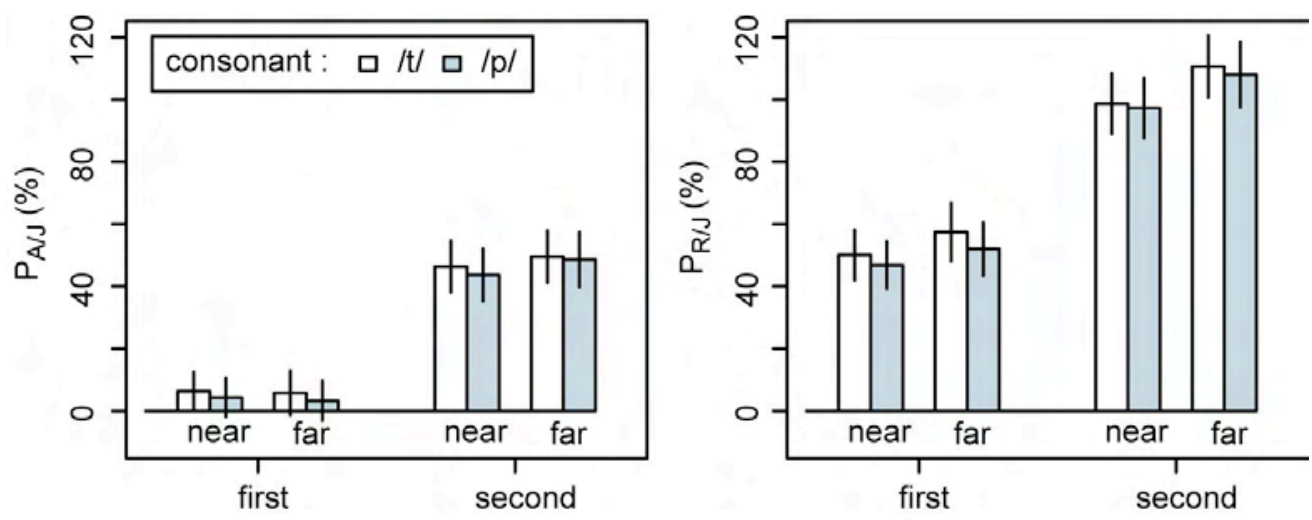

Stress position $\mathrm{X}$ Target position

Figure 4. Means and standard errors of the time of the pointing apex (PA/J, left) and of the time of the onset of the pointing return $(P R / J$, right) relative to the apices of the two jaw opening gestures, depending on stress position (first vs. second syllable), target position (near vs. far) and consonant (/t/ vs. /p/). $111 \times 48 \mathrm{~mm}(300 \times 300 \mathrm{DPI})$ 

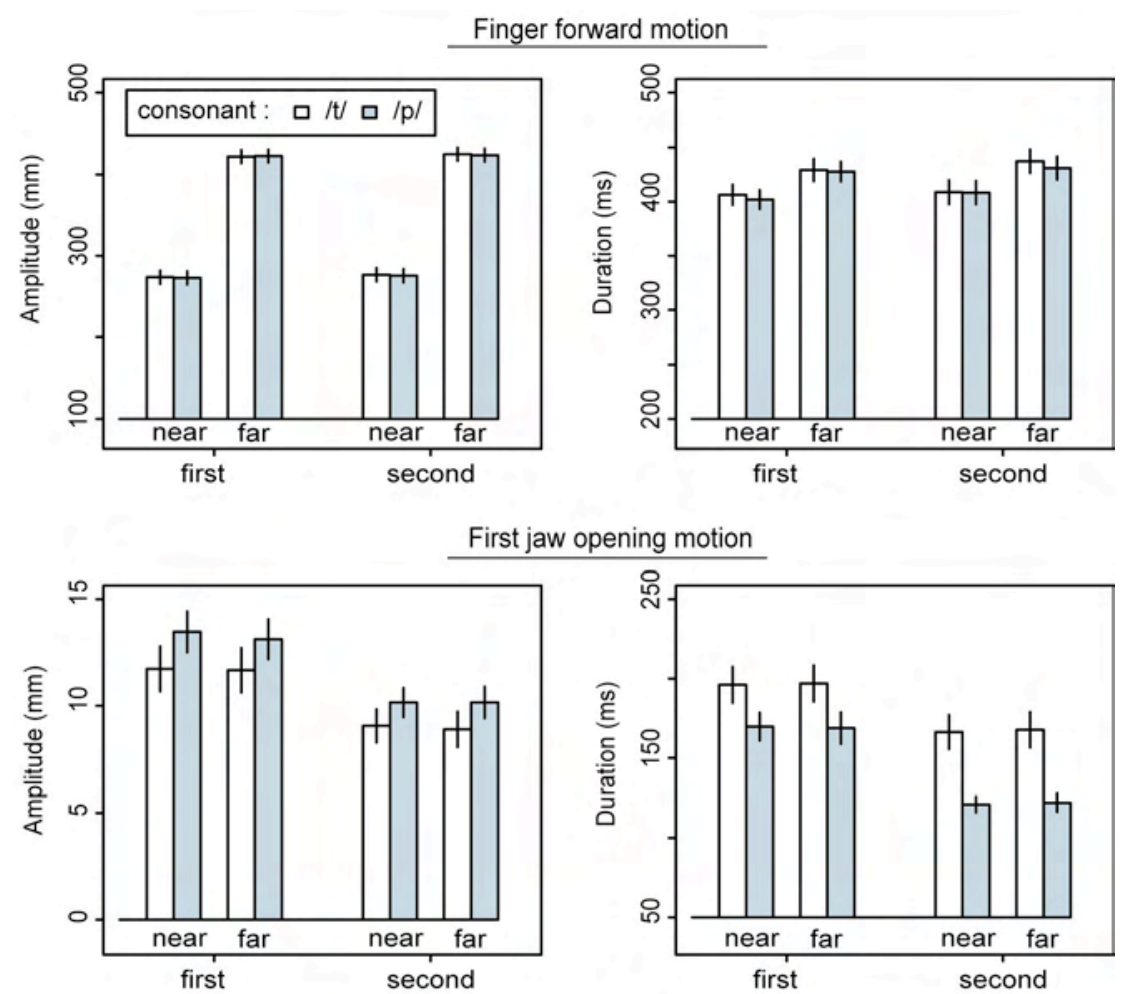

Second jaw opening motion
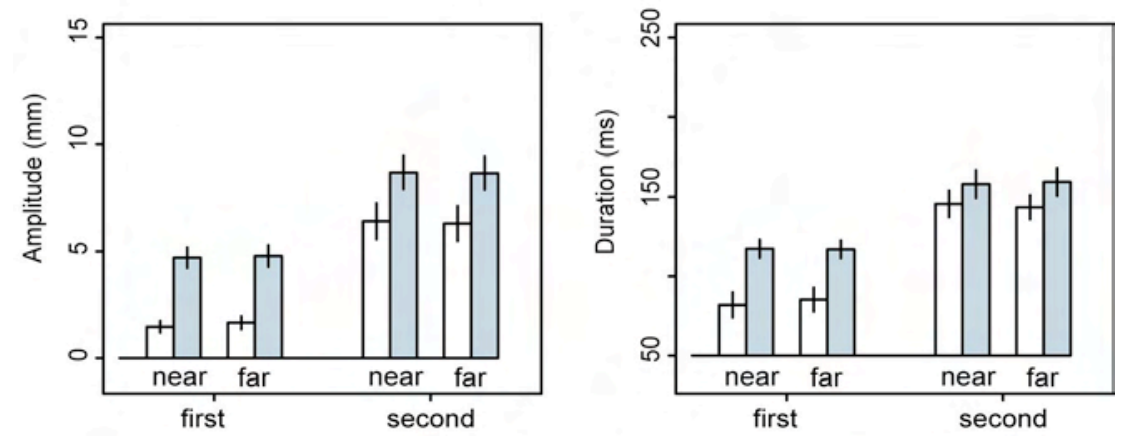

Stress position $X$ Target position

Figure 5. Means and standard errors of the amplitude and the duration of the finger forward stroke (first row) and of the two jaw opening strokes (second and third rows) depending on stress position (first vs. second syllable), target position (near vs. far) and consonant (/t/ vs. /p/).

$111 \times 158 \mathrm{~mm}(300 \times 300 \mathrm{DPI})$ 